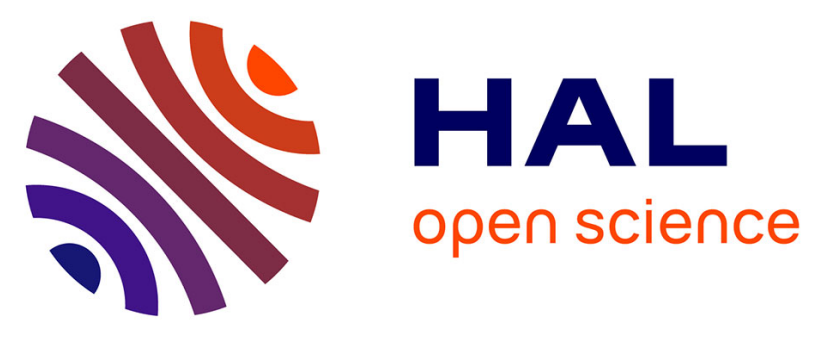

\title{
Pierre Turq, an inspirational scientist in charge and at interfaces
}

\author{
Bernard Ancian, Olivier Bernard, Jean Chevalet, Vincent Dahirel, Didier \\ Devilliers, Emmanuelle Dubois, Jean-François Dufrêche, Serge Durand-Vidal, \\ Henri Groult, Marie Jardat, et al.
}

\section{To cite this version:}

Bernard Ancian, Olivier Bernard, Jean Chevalet, Vincent Dahirel, Didier Devilliers, et al.. Pierre Turq, an inspirational scientist in charge and at interfaces. Molecular Physics, 2014, 112 (9-10), pp.1213-1221. 10.1080/00268976.2014.885094 . hal-01484053

\section{HAL Id: hal-01484053 \\ https://hal.sorbonne-universite.fr/hal-01484053}

Submitted on 8 Nov 2018

HAL is a multi-disciplinary open access archive for the deposit and dissemination of scientific research documents, whether they are published or not. The documents may come from teaching and research institutions in France or abroad, or from public or private research centers.
L'archive ouverte pluridisciplinaire HAL, est destinée au dépôt et à la diffusion de documents scientifiques de niveau recherche, publiés ou non, émanant des établissements d'enseignement et de recherche français ou étrangers, des laboratoires publics ou privés. 


\title{
Pierre Turq, an inspirational scientist in charge and at interfaces
}

\author{
Bernard Ancian $^{a, b}$, Olivier Bernard ${ }^{a, b}$, Jean Chevalet $^{a, b}$, Vincent Dahirel $^{a, b}$, Didier \\ Devilliers $^{a, b}$, Emmanuelle Dubois ${ }^{a, b}$, Jean-François Dufrêche ${ }^{c}$, Serge Durand-Vidal ${ }^{a, b}$, \\ Henri Groult $^{a, b}$, Marie Jardat ${ }^{a, b *}$, Frédéric Lantelme ${ }^{a, b}$, Natalie Malikova ${ }^{a, b}$, Virginie \\ Marry $^{a, b}$, Guillaume Mériguet ${ }^{a, b}$, Régine Perzynski ${ }^{a, b}$, Anne-Laure Rollet $^{a, b}$, Benjamin \\ Rotenberg $^{a, b}$, Mathieu Salanne ${ }^{a, b}$, Christian Simon $^{a, b}$ \\ ${ }^{a}$ Sorbonne Universités, UPMC Univ Paris 06, UMR PHENIX, F-75005, Paris, France; \\ ${ }^{b}$ CNRS, UMR PHENIX, F-75005, Paris, France; \\ ${ }^{c}$ CEA, CNRS, UM2, ENSCM, UMR 5257, Inst Chim Separat Marcoule, F-30207 \\ Bagnols Sur Ceze, France; \\ (December 16, 2013)

\begin{abstract}
Pierre Turq has made decisive contributions to the theory and to the multiscale simulation of charged systems, such as molten salts, electrolyte solutions and colloidal suspensions, in the bulk, at interfaces and under confinement. His research line focussed on dynamical properties and was characterized by constant efforts to connect his theoretical work to both experiments and practical applications. In this article, his colleagues and former students pay a tribute to his past and current research interests by illustrating some recent developments accomplished in his laboratory.
\end{abstract}

\section{Introduction}

Pierre Turq has made decisive contributions to the theory and to the multiscale simulation of charged systems, such as molten salts, electrolyte solutions and colloidal suspensions, in the bulk, at interfaces and under confinement. His focus on dynamical properties, reflected in particular by his pioneering works using Brownian Dynamics for the simulation of electrolytes solutions, as well as his constant efforts to connect his theoretical work to both experiments and practical applications, have shaped the research performed in the former Laboratoire Liquides Ioniques et Interfaces Chargées (LI2C), which he created and directed before its evolution to the Laboratoire Physicochimie des Electrolytes, Colloïdes et Sciences Analytiques (PECSA) into the new Laboratoire Physicochimie et Electrochimie des Colloïdes et Nanosystèmes Interfaciaux (PHENIX). In this article, his colleagues and former students pay a tribute to his past and current research interests by illustrating some recent developments accomplished in his laboratory.

The paper is organized as follows: Sections 2 and 3 first illustrate the latest developments of analytical theories and mesoscopic simulations, respectively, for the study of charged systems. Then, several applications are discussed: electrolyte solutions and colloidal suspensions in Section 4, porous media in Section 5 and finally molten salts in Section 6, .

${ }^{*}$ Corresponding author. Email: marie.jardat@upmc.fr 


\section{Analytical theories}

P. Turq developed analytical theories and numerical simulations of charged systems in parallel. With the considerable increase in performance of scientific computing in the last decades, one can nowadays perform accurate simulations that were difficult or impossible during the early stages of his career. At first glance, it may then seem less useful to develop analytical models that are more approximate by nature. However, although simulations allow in principle to compute macroscopic quantities with fewer approximations than analytical theories, the results depend in practice on a variety of parameters to describe the interactions within the system of interest. In addition, the computational cost associated with such simulations may render the systematic variation of the model parameters difficult - a step which is often necessary for the comparison with experimental data. On the contrary, analytical theories, which provide results at little cost, allow for such studies. Even today, they remain the core of calculations of industrial or geochemical processes, which require the description of large, inhomogeneous and time-dependent systems, with time and length scales beyond the reach of particle-based or mesoscopic simulations.

Most analytical theories of charged species in solution considered only the description of static equilibrium properties (structure and thermodynamics). Under the impulse of P. Turq, the analytical modeling work in his group has rather focused on the transport properties of these systems. The studies initially aimed at two transport quantities among the best known experimentally, namely the selfdiffusion coefficient of ions and conductivity of binary electrolyte solutions, as well as their dependance on concentration. For such systems, the description of the properties is done mainly in the context of continuous solvent models, wherein the ions interact via potentials averaged over the solvent degrees of freedom (MacMillanMayer level). The ions, seen as charged hard spheres in the so-called Primitive Model of electrolytes, were initially described using the theories of Debye, Hückel and Onsager, which apply only for concentrations lower than $10^{-2}$ mol.L ${ }^{-1}$. Using the latest developments in statistical mechanics, in particular the work of L. Blum (Mean Spherical Approximation, MSA), H. Friedman and W. Ebeling (transport at the Smoluchowski level) and B. Bagchi (Mode Coupling Theory), P. Turq's team extended the description of transport properties to more concentrated solutions and to colloidal suspensions, as well as to other phenomena, such as mutual diffusion or acousto-phoresis [1]. One of the main contribution has been to include the effect of hydrodynamic interactions between ions, accounting for their finite size, and the coupling between long-range hydrodynamic and electrostatic interactions.

A continuous line of research in his group has been the comparison of analytical theories with both experimental data on the thermodynamic and transport properties and numerical simulations performed in the group at the same level of description of the system, in particular with Brownian Dynamics (for a review, see [2]). While the former comparison allows to determine the parameters associated with a given experimental system (e.g. hydrated ionic radii), the latter allows to assess the validity of analytical theories for a given description of that system. One of the successes achieved in recent years is the ability to describe the properties of electrolyte mixtures, such as their conductivity, only from the knowledge of the parameters for the simple binary electrolytes [3]. The group has also extended this analytical approach to various complex systems (see following sections), including e.g. micellar systems $[4,5]$ clay powders $[6,7]$, or humic and fulvic acids which are ionized in aqueous solutions [8, 9]. This latter application is illustrated in Figure 1.

Recent developments also include the improvement of the continuous solvent models underlying these analytical theories. While the ions are generally treated 


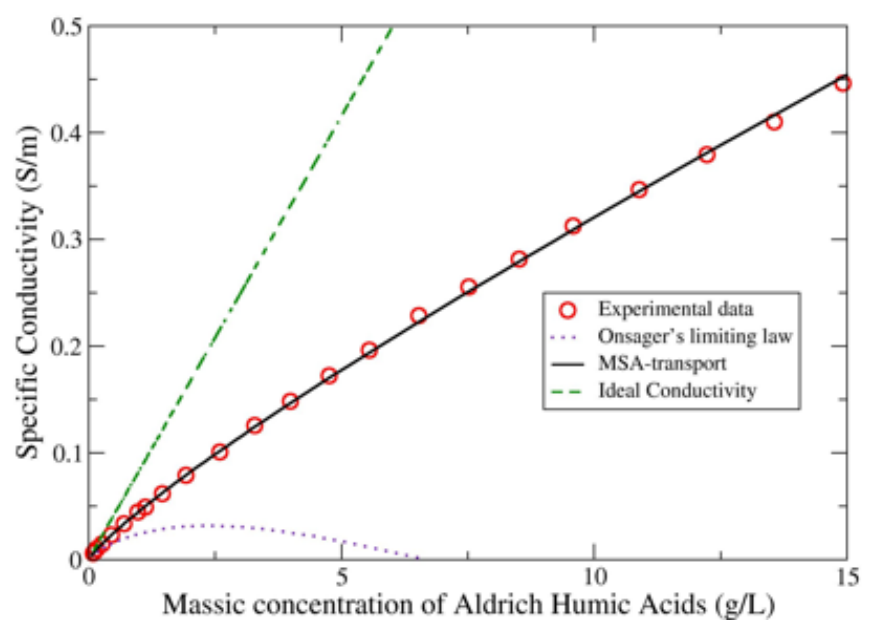

Figure 1. Electrical conductivity of humic acid solutions at $\mathrm{pH}=8$ and $298.15 \mathrm{~K}$ as a function of concentration: experimental data (circles), MSA-transport calculations (solid line); ideal conductivity (dashed line) and Onsager limiting law (dotted line). Reprinted from [8] with permission from Elsevier.

as charged hard spheres, using in addition linearized theories to determine their static and dynamic properties, such a description fails to account for interactions at short distance, in particular when the electric charge of these ions is large, or when the dielectric constant of the solvent is low. Other kinds of interactions (specific or chemical) may also play an important role at short distance. In collaboration with L. Blum, P. Turq's group extended the MSA theory, applied in this context only to charged hard spheres, by also taking into account short range attractive potentials. This extension was then successfully applied to the properties of actinide or lanthanide aqueous solutions, also in the presence of concentrated nitric acid [1014], and to bulky ions in solution, as a first step toward the description of ionic liquids as alternative media for synthesis, separation or liquid-liquid extraction [15].

Finally, these short-range interactions can be extracted from all-atom molecular simulations, in the framework of a multi-scale coarse-graining strategy. More precisely, the effective potential between two ions in solution, averaged over the solvent degrees of freedom, can be computed directly from molecular simulations, or more efficiently using a variational approach based on analytical theories for the free energy of the ionic solutions [16-18]. Taking into account the specific shortrange interactions derived from molecular simulations improves the description of thermodynamic properties. The application to transport with analytical theories and mesoscopic simulations remains to be investigated.

\section{Simulation at the mesoscopic scale}

The second class of theoretical tools for the description of transport in charged systems in which P. Turq and his collaborators were involved, is computer simulation. In particular, P. Turq's team largely contributed over the years to the development of simulation schemes able to investigate the dynamics of ions and charged nanoparticles in solution, as well as the dynamics of charged species under confinement.

Algorithms based on continuous solvent models that account for the Brownian fluctuations induced by the solvent were introduced in the 1970's. In a pioneering work done in collaboration with F. Lantelme and H.-L. Friedman [19], P. Turq proposed an algorithm based on a generalized Langevin equation, firstly applied to compute the self-diffusion coefficients of ions in aqueous solutions. Another famous 
algorithm for Brownian Dynamics (BD) simulation was proposed by Ermak [20] which was based on an overdamped Langevin equation. Nevertheless, both these algorithms neglect the momentum transport through the solvent which leads to long range hydrodynamic interactions (HIs) between solutes. Shortly thereafter, Ermak and McCammon thus proposed to add a simple representation of HIs to the overdamped Langevin equation using an approximate mobility matrix instead of the scalar friction coefficient [21]. Brownian dynamics simulations with HIs following the Ermak and McCammon algorithm became extremely popular to study the kinetics of biological reactions but were seldom applied to the case of ionic solutions [22]. Indeed, from the computational point of view, BD simulations have two weaknesses: (i) Computing the stochastic displacement requires at each simulation step the evaluation of the square root of the mobility tensor, which is a time consuming operation, (ii) For systems where steep short-range repulsions or deep minima exist, such as systems with electrostatic interactions, extremely small time steps must be used to avoid unphysical displacements due to the stochastic contribution.

To enhance the efficiency of BD simulations, many efforts have been devoted to the computation of the square root of the mobility matrix, and several approximations have been proposed [23-25]. Another strategy is to increase the time step while keeping trajectories as close as possible to the ones that would be obtained in the zero time step limit. In 1999, such an efficient scheme was proposed by the team of P. Turq [26]: At each time step, the probability of the solutes displacements are computed thanks to a smart Monte Carlo algorithm [27]. This method was shown to provide reliable estimates of the self-diffusion coefficients of ions and of the electrical conductivity for simple electrolyte solutions [26, 28, 29] and micellar solutions $[4,30,31]$ described by the primitive model of electrolytes. Moreover, it was shown that HIs enhance the self-diffusion coefficient of solutes, in agreement with mode-coupling results [32].

The group also extended the BD scheme in order to study the dynamic properties of charged nanoparticles in solution: The different length and time scales associated with nanoparticles and small ions make this task a real challenge. In particular, the simulation must be long enough to ensure a sufficient displacement of the slowest particle. To achieve this goal, a multiscale strategy based on BD was introduced. Within this new procedure, two BD simulations are performed: (1) The first one investigates the time scales of the counterions and coions with only one nanoparticle in the simulation box but explicit microions, (2) The second one investigates the longer time scale of the nanoparticles, with numerous nanoparticles in the simulation box but implicit microions. This is illustrated on Figure 2. This allowed us to calculate for a model system each transport coefficient (selfand mutual diffusion coefficients, electrical conductivity, electrophoretic mobility) with a high accuracy and a short computational time [33, 34].

Nevertheless, the treatment of HIs in BD suffers from other limitations: Pairwise approximations of the diffusion tensor exist for bulk solutions but scarcely for systems under confinement, and even in the bulk such approximations are valid only for dilute systems (typically with volume fractions smaller than 10\% [36]). An appealing coarse-grained simulation method which allows one to overcome both these difficulties has been proposed by Malevanets and Kapral in 1999 [37]. In this Stochastic Rotation Dynamics (SRD) algorithm, also named Multiple Particle Collision Dynamics [38], the fluid is represented by point particles that only interact through the so-called collision steps where momentum exchanges occur. Between collision steps, fluid particles undergo ballistic motion. As this algorithm conserves momentum and energy, it generates the correct Navier-Stokes hydrodynamics. In 


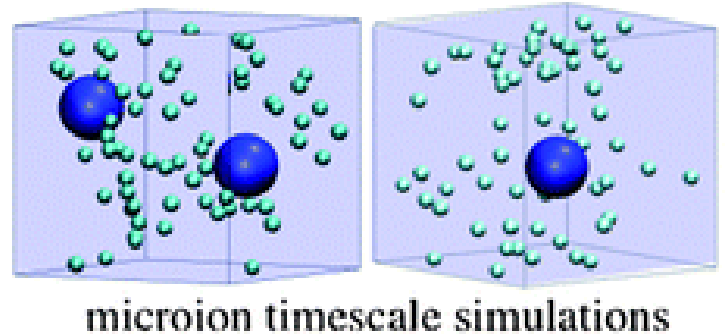

microion timescale simulations

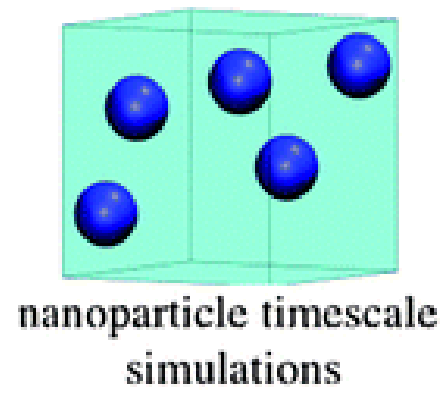

simulations

Figure 2. Principle of a two-scale Brownian Dynamics simulation of nanoparticle suspensions: Simulations with explicit micro-ions first provide the Potential of Mean Force between two nanoparticles and the selfdiffusion coefficient of a single nanoparticle, which are then used in simulations where the effect of micro-ions is accounted for implicitely. Reproduced from [35] with permission from The Royal Society of Chemistry.

order to describe solutions and suspensions, a fluid bath described via SRD can be coupled to an explicit molecular dynamics of interacting solute particles.

The group recently applied this simulation method to the description of the transport properties of suspensions of charged solutes, performing in particular a thorough comparison of two ways of coupling solutes to the solvent with SRD from the literature to BD with and without explicit HIs. This study showed that one of the coupling scheme, whereby the solutes interact through direct forces with the solvent, generating slip boundary conditions, provides results similar to those of $\mathrm{BD}$ with HIs for the diffusion coefficients and for the electrical conductivity. The other coupling scheme, in which solutes participate in the collisional step, predicts diffusion coefficients close to those obtained by BD simulations without HIs but accounts for part of the influence of hydrodynamics on the electrical conductivity [39]. Our comparative study also showed that, from the point of view of numerical efficiency, $\mathrm{BD}$, because it is based on an overdamped equation of motion and assumes that the solvent is a continuous medium, is much more efficient than SRD-based simulations to compute trajectories over time scales larger than the diffusion time scale. Of course, outside the range of application of BD (i.e. for concentrated systems and systems under flow or under confinement), resort to SRD-based or other algorithms is mandatory.

The description of the transport of charged species through complex porous media requires an even coarser description and the group also participated in the development of another mesoscopic simulation method, which couples a hydrodynamic description to a free energy functional accounting for the interactions between solvent and charged solutes. This method, called Lattice Boltzmann Electrokinetics (LBE) is implemented in a hybrid lattice-based algorithm [40]. The team proposed recently to extend this scheme in order to account for the osmotic contribution to the transport of ions and solvent in charged porous media [41]. Moreover, LBE calculations were validated against approximate analytic expressions of all the transfer coefficients which couple the solvent and ionic fluxes through a charged pore under the effect of pressure, electrostatic potential, and concentration gradients at the Poisson-Nernst-Planck and Navier-Stokes levels of description [41]. Current developments include the use of these transfer coefficients as input for coarser descriptions of transport on larger scales in the framework of the pore network model, wherein the void space of the porous medium is represented by an idealized geometry of pores joined by channels. 


\section{Electrolytes solutions and colloidal suspensions}

All the theoretical developments introduced by P. Turq, whose current outcomes have been described above (see Sections 2 and 3), were always very close to the experimental determination of the properties under scrutiny. Here follow three notable examples of recent research on topics inspired by P. Turq: electrolytes, micellar systems and colloidal dispersions.

\subsection{Electrolytes}

Since the beginning of his scientific career, one of P. Turq's main interest has been the dynamics of small charged systems, namely electrolyte solutions, for which his contribution is substantial. Even if this subject might now appear rather outdated, some properties remain to be unveiled as Werner Kunz, one of P. Turq's former post-doctoral students, admits in his recent book on specific ion effects [42]:

It is still a fact that over the last decades, it was easier to fly to the moon than to describe the free energy of even the simplest salt solutions beyond a concentration of 0.1 mol. $\mathrm{L}^{-1}$ or so.

The use of both analytical theories and mesoscopic simulations made it possible to investigate the dynamic properties of concentrated electrolyte solutions, mainly self-diffusion coefficients [32] and electrical conductivity [3, 26, 28, 29], since experimental data are rather easily found in the literature or can be determined e.g. by PFG-NMR or radiotracer techniques [43-45]. For more complex ions, such as larger hydrophobic ones, the great complementarity between the theoretical methods described above and neutron scattering allowed us to understand not only the structure of these solutions $[46,47]$ but also their dynamics with the help of quasielastic scattering experiments [48]. The theoretical approaches initiated by P. Turq also allowed to shed some light on the electro-acoustic phenomenon in electrolyte solutions [1].

\section{2. $\quad$ Micelles}

One of the first contributions of P. Turq on micellar systems was to assess the influence of the micelle-monomer exchange on the diffusion coefficient $[49,50]$. If the normal mode approach used then still remains insightful [35], other analytical theories (mainly MSA-Transport) have been successfully used to assess the charge and the radius of micellar aggregates from conductivity measurements, taking into account the interactions between all charged species in solution [4]. This method has also proven successful to determine the extent of premicellization, that is the formation of small surfactant aggregates before the critical micellar concentration $(\mathrm{cmc})$ : The shorter the chain of the surfactant, the larger the pre-micellization [5].

The mesoscopic simulations initiated by P. Turq have also been efficiently used on micellar systems to understand their dynamics or to derive effective charges [31]. More recently, a very efficient scheme described in Section 3 was developed using a two-scale BD strategy, taking into account the direct and hydrodynamics interactions between all solutes in solution. The associated reduction in computational cost compared to BD with explicit micro-ions made it possible to include it in a fitting procedure, opening the way to the efficient and accurate determination of the hydrodynamic radius of micelles in solution from PFG-NMR measurements [35] (see Figure 3). The parameters derived from this method are more robust than if they were obtained from analytical formulæ, since the simulations avoid most 
approximations included in the analytical treatments.

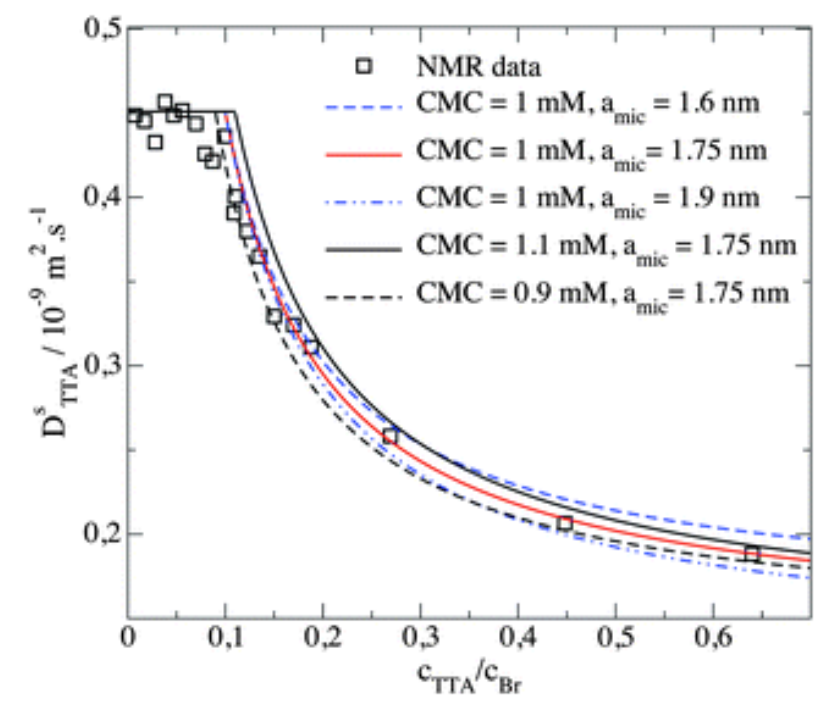

Figure 3. NMR self-diffusion coefficient of Tetradecyl-Trimethyl-Ammonium Bromide (TTA) as a function of its concentration, in presence of sodium bromide, for a fixed total bromide concentration $c_{\mathrm{Br}}=10 \mathrm{mM}$. Lines are theoretical predictions for different micelle radii $a_{\text {mic }}$ and critical micellar concentrations CMC. Reproduced from [35] with permission from The Royal Society of Chemistry.

\subsection{Colloids}

If the main application of the theoretical tools initiated by P. Turq has been devoted to charged systems, with particular focus on electrolyte solutions, they have recently been extended to other features of colloidal suspensions. One example is the dispersion of magnetic nanoparticles, often called ferrofluids. For these systems, the use of BD (see Section 3) made it possible to understand how the structure of these dispersions is modified under the influence of an external magnetic field, as probed by Small-Angle Neutron-Scattering (SANS) [51]. Our study confirmed that the strong electrostatic repulsion needed to ensure the colloidal stability of the dispersion is predominant, but that this repulsion is modulated by the applied field.

Experimentally, the orientation of the particles can be determined not only from the sample magnetization but also, since the nanoparticles display an anisotropy of optical index, from the birefringence of the suspension. Using BD, we could evaluate not only the stationary properties for a constant external field, but also the response of the system to a pulse of magnetic field, thanks to a non-equilibrium simulation [52], that can be directly compared to the equivalent experimental determination [53]. From these simulations, is appears that the relaxation process markedly slows down with increasing volume fraction, whereas hydrodynamic interactions have a small but systematic effect of lengthening the relaxation times. The dynamical process are mainly driven by the strong dipolar interaction caused by the initial alignement of the magnetic dipoles during the pulse.

\section{Porous materials}

A final example of systems involving charged interfaces for which P. Turq's impulse has fostered many developments is that of porous materials. Their study is a natural 
extension of that of colloidal suspensions, as the porous solid can be seen, from the point of view of the charged fluid embedded in the pores, as their concave counterpart, in a regime of very high solid to liquid ratio. The properties of the pore fluid differ from that in the bulk due to both the presence of interfaces with the solid walls and, in particular as far as dynamical processes are concerned, the geometric effects of confinement. Here follow examples of porous materials investigated in P. Turq's laboratory in the contexts of Energy and environmental applications.

\subsection{Ionomer membranes}

An example of P. Turq's early interest in charged porous materials is that of ionomer membranes such as Nafion. Ionomers are appealing systems because they are intermediate between polyelectrolytes and non charged polymers. The moderate amount of charges they carry, ca. 1-2 meq/g, induces a complex organization inside the membrane with hydrophobic and hydrophilic domains. The latter provide a network where water and ions can move. The pioneering approach of Turqs team was to combine on the one hand several experimental techniques (quasi-elastic neutron scattering, NMR and radiotracer) in order to provide a multiscale insight into the transport inside the membrane $[43,45]$ and on the other hand to combine the advanced theoretical tools (MSA-transport theory) and experiments in order to interpret conductivity and dielectric spectroscopy experiments [54].

\subsection{Clays}

The most studied porous materials in his group are clay minerals, in the context of the geological disposal of nuclear waste. These lamellar aluminosilicates display a variety of pores covering several orders of magnitude in size. On the molecular scale, interlayer pores between the charged mineral layers contain counterions and may swell due to the hydration of the latter. Larger pores between stacks of clay layers (called particles), with sizes in the range of hundreds of nanometers, contain fluids with properties closer to the bulk ones, even though the charged solid/fluid interfaces play an important role due to the long range of electrostatic and hydrodynamic interactions.

P. Turq's group investigated the interlayer structure and dynamics using a combination of molecular simulation (molecular dynamics and Monte Carlo) and experimental tools. In particular, water diffusion coefficients in the interlayer nanopores of natural and synthetic clays could be measured on time scales comparable to molecular simulations using QENS experiments (time-of-flight and spin echo). The diffusion of water is slowed down when confined between clay layers separated by distances lower than $20 \AA[55,56]$. Conversely, the comparison with experiments demonstrated the shortcomings of the force fields used in molecular simulations $[57,58]$. Understanding the dynamics of interlayer cations on the molecular scale allowed to propose a simple diffusion/adsorption scheme [59], which was then used to model some relaxation processes for the interpretation of dielectric spectroscopy experiments $[5,6,60]$. The group further studied the dynamics and thermodynamics of water and ion exchange between the smallest (interlayer) and larger (interparticle) pores by combining of molecular simulations with microcalorimetry experiments [61, 62]. Future NMR relaxometry experiments analyzed in the light of molecular simulations should provides new insight into dynamical processes over a wide range of time scales.

The behaviour of the first fluid layers in interparticle pores deviates from that of 


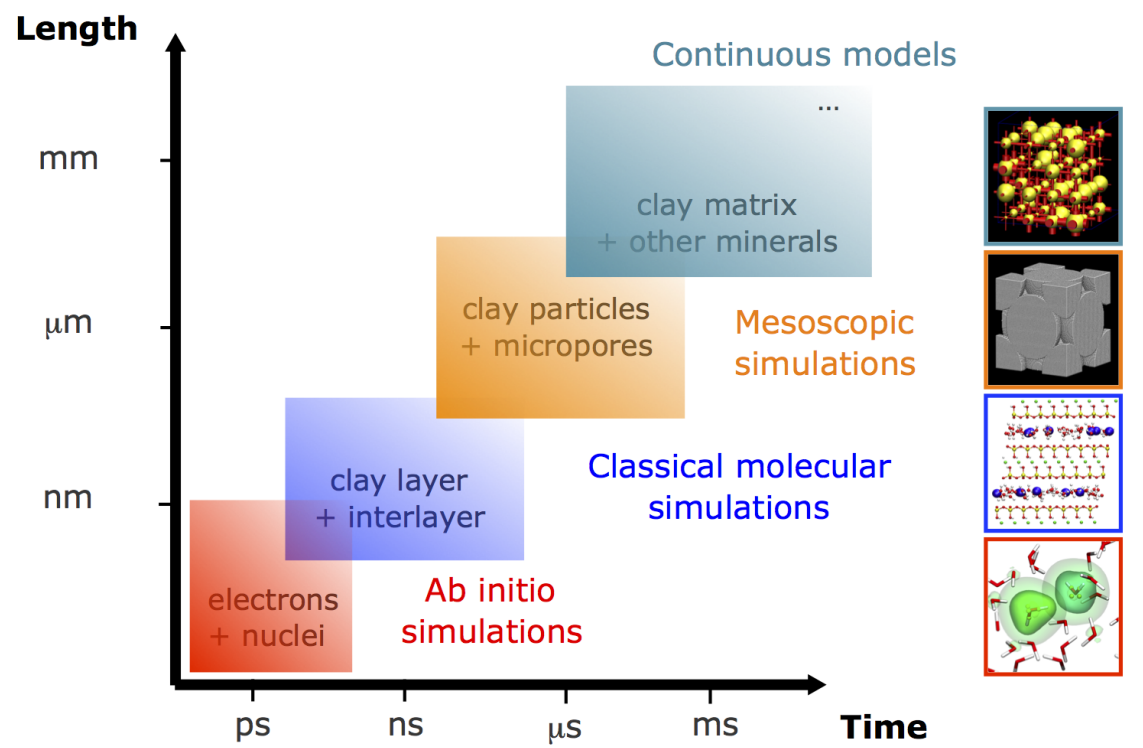

Figure 4. Multiscale simulations used to deal with the wide range of length and timescales over which relevant processes occur in clays: From ab initio simulations to investigate the reactivity of surface sites to highly coarse-grained models described in Section 3, including many studies on the molecular scale using classical molecular simulations. Each level of description can be calibrated on a finer one, in the framework of a bottom-up approach.

the bulk liquid. This was shown by the analysis on the molecular scale the structure and dynamics of water and adsorbed ions [63], including in the presence of $\mathrm{CO}_{2}$ for applications to the sequestration of this greenhouse gas in saline aquifers [64]. The wettability of clay minerals depends on delicate balance of interactions with the surface [65] and has an important influence on the hydrodynamic behaviour (stick or slip) of the surface [66, 67], as also observed e.g.in silica nanopores [68]. Such a molecular scale understanding of the mineral/water interface also provided the basis of improved mesoscopic models with an implicit solvent [67, 69, 70], which can be used for the simulation on larger scales, as illustrated in Figure 4. Such simulations will greatly benefit from the recent developments of imaging techniques, which should provide realistic descriptions of these complex materials, and of the modelling tools described in Section 3.

\subsection{Nanoporous carbons}

A last recent example of studies on porous media is that of ionic liquids confined in nanoporous carbon electrodes, with applications to electric energy storage in supercapacitors. In collaboration with the experimental group of P. Simon (Université Paul Sabatier, Toulouse, France), the team investigated using molecular simulation the microscopic processes at the origin of the large capacitance observed with carbide derived carbons (CDCs) electrodes. This study demonstrated how the charging mechanism in these materials differs from that at a planar graphite electrode [71] and that highly confined ions store charge more efficiently in the nanopores [72].

\section{Molten salts}

A final class of systems investigated by P. Turq and in which his group is still active is that of molten salts, which are high temperature liquids consisting only of 
ionic species. They do not contain any neutral molecule and are often considered as "solvent-free" electrolytes. They can be used in many contexts, ranging from metal production [73] to solar [74] and Generation IV nuclear power plants [75, 76]. Understanding the transport properties of molten salts is therefore of particular importance. Nevertheless, due to their high melting points and their corrosive behaviour, the study of molten salts often requires the development of original experimental setups. In addition, due to their large charge density, simple liquid theories often do not apply. To overcome these difficulties, in collaboration with F. Lantelme, P. Turq performed a series of pioneering molecular dynamics studies on the properties of molten chlorides [77-80]. This allowed them to determine in particular the isotope substitution [78] and mixing [79] effects on the self-diffusion coefficients. Experimental and theoretical works in the group also contributed to a better understanding of molten KF-2HF mixtures, with application to fluorine production [81]. More recently, P. Turq started a fruitful collaboration with the group of P. Madden in order to study molten fluorides, in the context of the Molten Salt Fast Reactor project [82].

For being predictive, the molecular dynamics simulations, which use polarizable interaction potentials [83], need first to be validated on the largest possible amount of experimental data. In molten fluorides, many transport properties remain unknown, so that a strategy based on systematic measurements of the electrical conductivity was set up [84]. This property was chosen because of its collective nature. If the self-diffusion coefficients are also known [85], it allows to determine the importance of the cross-correlations between the ionic species. It therefore provides an excellent test of the interaction potentials used in the simulations. Experimentally, the electrical conductivity is obtained by an electrochemical method, i.e. by impedance measurements at the open circuit potential. In simulations, it can either be determined from the electric current auto-correlation function (using a GreenKubo relation) or from the mean-squared displacements of the ions (taking into account all the cross-correlations).

Mixtures of $\mathrm{LiF}-\mathrm{NaF}-\mathrm{ZrF}_{4}$ and $\mathrm{LiF}-\mathrm{YF}_{3}$ with varying compositions were investigated [84-86]. In all cases, a very good agreement between experiments and simulations was obtained. The first implication is that the latter, which were also validated on structural properties [82] could then be used to determine other properties, such as the viscosity, the heat capacity, the thermal conductivity, etc. All these properties are important for the design of a nuclear reactor. But the knowledge of the electrical conductivity of a molten salt is also useful for understanding its particular physical chemistry. A first hint on the impact of the structure on the transport properties can be obtained by comparing the calculated/measured electrical conductivity with the Nernst-Einstein approximation,

$$
\kappa^{\mathrm{NE}}=\frac{e^{2}}{k_{B} T} \sum_{i} \rho_{i} z_{i}^{2} D_{i}
$$

in which $k_{B}$ is the Boltzmann constant, $T$ the temperature, $e$ the elementary charge; $\rho_{i}, z_{i}$ and $D_{i}$ are respectively the number density, the algebraic charge and the self-diffusion coefficient of ionic species $i$. This relation neglects the ionic correlations. In the special case of molten salts it is therefore expected to be a very poor approximation. Surprisingly, it provides an estimate of the correct order of magnitude [84]. In the LiF-NaF eutectic, the agreement is very good. In fact, this is due to the presence of strong cancellation effects between the various cross-terms, so this agreement does not mean that the Nernst-Einstein is valid in molten salts. As soon as $\mathrm{YF}_{3}$ or $\mathrm{ZrF}_{4}$ are present in the molten salt, the deviation 
of the real conductivity from the Nernst-Einstein one becomes more evident. This is due to the formation of particular coordination shells of fluoride anions around the multivalent $\mathrm{Y}^{3+}$ and $\mathrm{Zr}^{4+}$ cations, as illustrated in Fig. 5.

Indeed, our simulations showed that $\mathrm{Y}^{3+}$ and $\mathrm{Zr}^{4+}$ cations favor high coordination numbers, ranging from 6 to 9 (the distribution of coordination numbers vary with the composition of the molten salt). Therefore, when their concentration increases, larger Y-F and Zr-F cross-correlations occur in the melt, thus lowering both the absolute value of the electrical conductivity and its deviation from Nernst-Einstein equation. In parallel, an increase of the viscosity and a decrease of all the diffusion coefficients is also obtained. The lifetime of the Y-F and Zr-F bonds were evaluated by calculating the cage-out correlation functions, which measure the probability for one anion to leave the coordination shell of the cation at a given time. This analysis shows that the coordination shell of the zirconium ion is much longer lived, which explains that the slowdown of the transport properties is stronger in this melt than in the yttrium-based one.

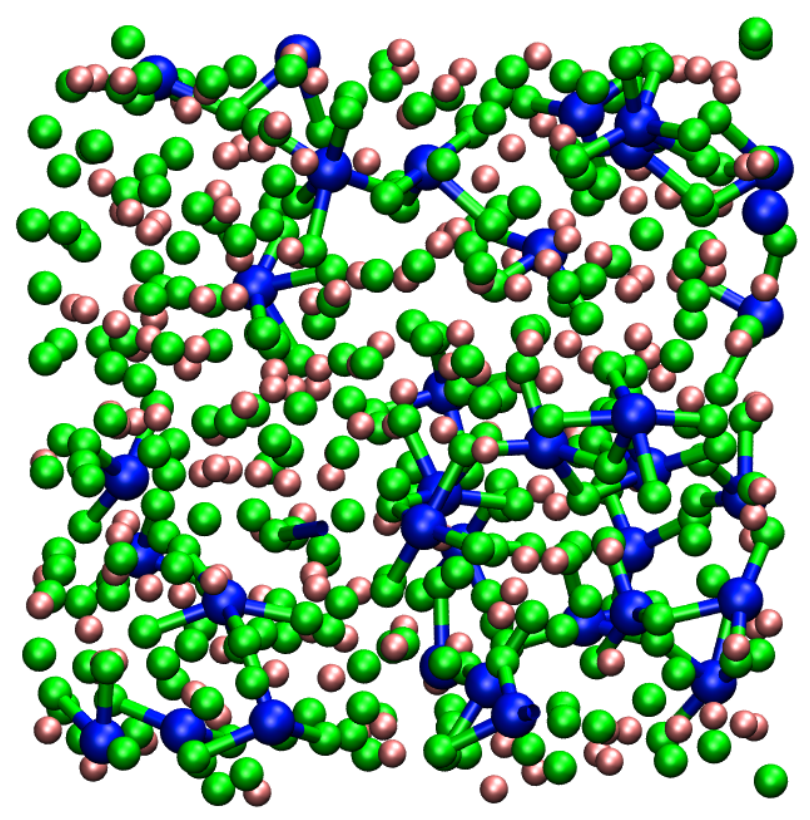

Figure 5. Snapshot extracted from a simulation of the LiF-YF 3 mixture at $x\left(\mathrm{YF}_{3}\right)=0.15$. Large blue spheres: $\mathrm{Y}^{3+}$, medium green spheres: $\mathrm{F}^{-}$and small pink spheres: $\mathrm{Li}^{+}$. Bonds are drawn for $\mathrm{Y}-\mathrm{F}$ pairs separated by less than $2.3 \mathrm{~A}$ illustrating the formation of a complex network of bonded species.

\section{Conclusion and perspectives}

Under the impulse of Pierre Turq, his former students and colleagues have come to appreciate the value of combining theoretical and experimental approaches, as well as the great source of information provided by dynamical properties. We would like to acknowledge his support and guidance and we wish him a happy seventieth birthday.

\section{References}

[1] S. Durand-Vidal, J.P. Simonin, P. Turq and O. Bernard, J. Phys. Chem. 99 (17), 6733 (1995).

[2] J.F. Dufrêche, O. Bernard, S. Durand-Vidal and P. Turq, J. Phys. Chem. B 109 (20), 9873 (2005). 
[3] G.M. Roger, S. Durand-Vidal, O. Bernard and P. Turq, J. Phys. Chem. B 113 (25), 8670 (2009).

[4] S. Durand-Vidal, M. Jardat, V. Dahirel, O. Bernard, K. Perrigaud and P. Turq, J. Phys. Chem. B 110 (31), 15542 (2006).

[5] G.M. Roger, S. Durand-Vidal, O. Bernard, P. Turq, T.M. Perger and M. Beśter-Rogac̆, J. Phys. Chem. B 112 (51), 16529 (2008).

[6] B. Rotenberg, A. Cadène, J.F. Dufrêche, S. Durand-Vidal, J.C. Badot and P. Turq, J. Phys. Chem. B 109 (32), 15548 (2005).

[7] B. Rotenberg, J.F. Dufrêche and P. Turq, J. Chem. Phys. 123 (15), 154902 (2005).

[8] G.M. Roger, S. Durand-Vidal, O. Bernard, G. Mériguet, S. Altmann and P. Turq, Colloids Surf. A 356 (1-3), 51 (2010).

[9] G.M. Roger, G. Mériguet, O. Bernard, S. Durand-Vidal and P. Turq, Colloids Surf. A 436 (1), 408 (2013).

[10] T. Vilariño, O. Bernard and J.P. Simonin, J. Phys. Chem. B 108 (18), 57635770 (2004).

[11] A. Ruas, P. Moisy, J.P. Simonin, O. Bernard, J.F. Dufrêche and P. Turq, J. Phys. Chem. B 109 (11), 5243 (2005).

[12] A. Ruas, O. Bernard, B. Caniffi, J.P. Simonin, P. Turq, L. Blum and P. Moisy, J. Phys. Chem. B 110 (7), 3435 (2005).

[13] J. Torres-Arenas, J.P. Simonin, O. Bernard, A. Ruas and P. Moisy, Ind. Eng. Chem. Res. 49 (4), 1937 (2010).

[14] S. Hlushak, J.P. Simonin, S. De Sio, O. Bernard, A. Ruas, P. Pochon, S. Jan and P. Moisy, Dalton Trans. 42 (8), 2853 (2013).

[15] N. Papaiconomou, J.P. Simonin and O. Bernard, Ind. Eng. Chem. Res. 51 (28), 9661 (2012).

[16] J.J. Molina, J.F. Dufreche, M. Salanne, O. Bernard, M. Jardat and P. Turq, Phys. Rev. E 80 (6), 065103 (2009).

[17] J.J. Molina, J.F. Dufrêche, M. Salanne, O. Bernard and P. Turq, J. Chem. Phys. 135 (23), 234509 (2011).

[18] J.J. Molina, M. Duvail, J.F. Dufrêche and P. Guilbaud, J. Phys. Chem. B 115 (1-2), 4329 (2011).

[19] P. Turq, F. Lantelme and H.L. Friedman, J. Chem. Phys. 66, 3039 (1977).

[20] D.L. Ermak, J. Chem. Phys. 62, 4189 (1975).

[21] D.L. Ermak and J.A. McCammon, J. Chem. Phys. 69, 1352 (1978).

[22] M.D. Wood and H.L. Friedman, Zeit. Phys. Chem. N. F. 155, 121 (1987).

[23] M. Fixman, Macromolecules 14, 1710 (1981).

[24] R.M. Jendrejack, M.D. Graham and J.J. de Pablo, J. Chem. Phys. 113, 2894 (2000).

[25] M. Kröger, A. Alba-Prez, M. Laso and H.C. Öttinger, J. Chem. Phys. 113, 4767 (2000).

[26] M. Jardat, O. Bernard, P. Turq and G.R. Kneller, J. Chem. Phys. 110, 7993 (1999).

[27] P.J. Rossky, J.D. Doll and H.L. Friedman, J. Chem. Phys. 69, 4628 (1978).

[28] M. Jardat, O. Bernard, C. Treiner and P. Turq, J. Phys. Chem. B 103 (40), 8462 (1999).

[29] M. Jardat, S. Durand-Vidal, P. Turq and G.R. Kneller, J. Mol. Liq. 85, 45 (2000).

[30] M. Jardat, S. Durand-Vidal, N. da Mota and P. Turq, J. Chem. Phys. 120, 6268 (2004).

[31] M. Jardat, V. Dahirel, S. Durand-Vidal, I. Lucas, O. Bernard and P. Turq, Mol. Phys. 104, 3667 (2006)

[32] J.F. Dufrêche, M. Jardat, P. Turq and B. Bagchi, J. Phys. Chem. B 112, 10264 (2008).

[33] V. Dahirel, M. Jardat, J.F. Dufrêche and P. Turq, J. Chem. Phys. 126, 114108 (2007).

[34] V. Dahirel, M. Jardat, J.F. Dufreêche and P. Turq, J. Chem. Phys. 131 (23), 234105 (2009).

[35] V. Dahirel, B. Ancian, M. Jardat, G. Mériguet, P. Turq and O. Lequin, Soft Matter 6 (3), $517(2010)$.

[36] A.J.C. Ladd, J. Chem. Phys. 93, 3484 (1990).

[37] A. Malevanets and R. Kapral, J. Chem. Phys. 110, 8605 (1999).

[38] G. Gompper, T. Ihle, D. Kroll and R. Winkler, Multi-Particle Collision Dynamics: A ParticleBased Mesoscale Simulation Approach to the Hydrodynamics of Complex Fluids, in Advanced Computer Simulation Approaches for Soft Matter Sciences III, edited by C. Holm and K. Kremer, Advances in Polymer Science, Vol. 221 (Springer, Berlin, 2009), pp. 1-87.

[39] G. Batôt, V. Dahirel, G. Mériguet, A.A. Louis and M. Jardat, Phys. Rev. E 88 (4) (2013).

[40] B. Rotenberg, I. Pagonabarraga and D. Frenkel, Faraday Discussions 144, 223 (2010).

[41] A. Obliger, M. Duvail, M. Jardat, D. Coelho, S. Békri and B. Rotenberg, Phys. Rev. E 88 (1) (2013).

[42] W. Kunz and R. Neueder, An Attempt of a General Overview, in Specific Ion Effects, edited by W. Kunz, Chap. 1 (World Scientific Publishing Co. Pte. Ltd., Singapore, 2009).

[43] A.L. Rollet, J.P. Simonin and P. Turq, Phys. Chem. Chem. Phys. 2 (5), 1029 (2000).

[44] A.L. Rollet, M. Jardat, J.F. Dufrêche, P. Turq and D. Canet, J. Mol. Liq. 92 (1-2), 53 (2001). 
[45] A.L. Rollet, G. Gebel, R. Kahn, J.P. Noël, A. Vandais, C. Malveau, D. Canet, J.P. Simonin and P. Turq, J. Phys. Chem. B 105 (9), 4503 (2001).

[46] P. Calmettes, W. Kunz and P. Turq, Physica B: Condensed Matter 180 \& 181, 868 (1992).

[47] W. Kunz, P. Calmettes, T. Cartailler and P. Turq, J. Chem. Phys. 99 (3), 2074 (1993).

[48] D. Bhowmik, N. Malikova, J. Teixeira, G. Mériguet, O. Bernard, P. Turq and W. Häussler, Eur. Phys. J. Special Topics 213 (1), 303 (2012).

[49] P. Turq, M. Drifford, M. Hayoun, A. Perera and J. Tabony, J. Physique Lett. 44 (12), 471 (1983).

[50] P. Turq, J.M.G. Barthel and M. Chemla, Transport, Relaxation, and Kinetic Processes in Electrolyte Solutions, Lecture Notes in Chemistry, Vol. 57 (Springer Berlin Heidelberg, Berlin, Heidelberg, 1992).

[51] G. Mériguet, M. Jardat and P. Turq, J. Chem. Phys. 121 (12), 6078 (2004).

[52] G. Mériguet, M. Jardat and P. Turq, J. Chem. Phys. 123 (14), 144915 (2005).

[53] G. Mériguet, E. Dubois, M. Jardat, A. Bourdon, G. Demouchy, V. Dupuis, B. Farago, R. Perzynski and P. Turq, J. Phys.: Condens. Matter 18, S2685 (2006).

[54] A. Lehmani, P. Turq, M. Périé, J. Périé and J.P. Simonin, J. Electroanal. Chem. 428 (1-2), 81 (1997).

[55] V. Marry and P. Turq, J. Phys. Chem. B 107 (8), 1832 (2003).

[56] N. Malikova, V. Marry, J.F. Dufrêche, C. Simon, P. Turq and E. Giffaut, Mol. Phys. 102 (18), 1965 (2004).

[57] N. Malikova, A. Cadène, E. Dubois, V. Marry, S. Durand-Vidal, P. Turq, J. Breu, S. Longeville and J.M. Zanotti, J. Phys. Chem. C 111 (47), 17603 (2007).

[58] V. Marry, E. Dubois, N. Malikova, J. Breu and W. Haussler, J. Phys. Chem. C 117 (29), 15106 (2013).

[59] B. Rotenberg, V. Marry, J.F. Dufrêche, E. Giffaut and P. Turq, J. Colloid Interf. Sci. 309 (2), 289 (2007).

[60] A. Cadène, B. Rotenberg, S. Durand-Vidal, J.C. Badot and P. Turq, Physics and Chemistry of the Earth 31 (10-14), 505 (2006).

[61] B. Rotenberg, V. Marry, R. Vuilleumier, N. Malikova, C. Simon and P. Turq, Geochimica and Cosmochimica Acta 71 (21), 5089 (2007).

[62] B. Rotenberg, J.P. Morel, V. Marry, P. Turq and N. Morel-Desrosiers, Geochimica and Cosmochimica Acta 73 (14), 4034 (2009).

[63] V. Marry, B. Rotenberg and P. Turq, Phys. Chem. Chem. Phys. 10 (32), 104205 (2008).

[64] A. Botan, B. Rotenberg, V. Marry, P. Turq and B. Noetinger, J. Phys. Chem. C 114 (35), $14962(2010)$.

[65] B. Rotenberg, A. Patel and D. Chandler, J. Am. Chem. Soc. 133 (50), 20521 (2011).

[66] J.F. Dufrêche, V. Marry, N. Malikova and P. Turq, Journal of Molecular Liquids 118 (1-3), $145(2005)$.

[67] A. Botan, V. Marry, B. Rotenberg, P. Turq and B. Noetinger, J. Phys. Chem. C 117 (2), 978 (2013).

[68] B. Siboulet, B. Coasne, J.F. Dufrêche and P. Turq, J. Phys. Chem. B 115 (24), 978 (2013).

[69] M. Jardat, J.F. Dufrêche, V. Marry, B. Rotenberg and P. Turq, Phys. Chem. Chem. Phys. 11 (12), 2023 (2009).

[70] M. Levesque, V. Marry, B. Rotenberg, G. Jeanmairet, R. Vuilleumier and D. Borgis, J. Chem. Phys. 137 (22), 224107 (2012).

[71] C. Merlet, B. Rotenberg, P.A. Madden, P.L. Taberna, P. Simon, Y. Gogotsi and M. Salanne, Nature Materials 11 (4), 306 (2012).

[72] C. Merlet, C. Péan, B. Rotenberg, P.A. Madden, B. Daffos, P.L. Taberna, P. Simon and M. Salanne, Nat. Commun. 4 (2013).

[73] G.Z. Chen, D.J. Fray and T.W. Farthing, Nature 407 (6802), 361 (2000).

[74] E. Cartlidge, Science 334, 922 (2011).

[75] L.C. Dewan, C. Simon, P.A. Madden, L.W. Hobbs and M. Salanne, J. Nucl. Mater. 434, 322 (2013).

[76] E. Sooby, A. Baty, O. Benes, P. McIntyre, N. Pogue, M. Salanne and A. Sattarov, J. Nucl. Mater. 440, 298 (2013).

[77] F. Lantelme, P. Turq, B. Quentrec and J.W.E. Lewis, Mol. Phys. 28, 1537 (1974).

[78] F. Lantelme and P. Turq, J. Chem. Phys. 67, 3869 (1977).

[79] F. Lantelme and P. Turq, J. Chem. Phys. 77, 3177 (1982).

[80] F. Lantelme and P. Turq, J. Chem. Phys. 81, 5046 (1984).

[81] H. Groult, S. Simon, A. Mantoux, F. Lantelme and P. Turq, in Fluorinated Materials for Energy Conversion",, edited by T. Nakajima and H. Groult (, , 2005), pp. 1-29.

[82] M. Salanne, C. Simon, P. Turq, R.J. Heaton and P.A. Madden, J. Phys. Chem. B 110, 11461 
(2006).

[83] M. Salanne and P.A. Madden, Mol. Phys. 109, 2299 (2011).

[84] M. Salanne, C. Simon, H. Groult, F. Lantelme, T. Goto and A. Barhoun, J. Fluorine Chem. 130, $61(2009)$.

[85] M. Levesque, V. Sarou-Kanian, M. Salanne, M. Gobet, H. Groult, C. Bessada and A.L. Rollet, J. Chem. Phys. 138, 184503 (2013).

[86] A.L. Rollet, M. Salanne and H. Groult, J. Fluorine Chem. 134, 44 (2012). 